\title{
An action research project to implement personal development plans into a community specialist practice programme
}

\author{
Liz Griffiths ${ }^{1}$, Lynn Sayer ${ }^{1}$, May Ryan ${ }^{1}$, Nessie \\ Shia ${ }^{1}$ and Rick Fisher ${ }^{2}$
}

Summary: This paper sets out to explore the implementation of Personal Development Planning both in university and professional practice settings for community health nurses, as an action research project. This was achieved through a series of cycles of implementation, review and modification using a collaborative approach. The introduction of this process into the course design has enabled all those involved to record student progress in an effective manner. Our findings show that community health students and their assessors in practice have found the experience a very positive one and as a result some "tips for best practice" have been developed that will help take the process further.

Keywords: Personal Development Plan, PREP, action research, community nursing

1. Lecturer in Community Health Nursing, Department of Health and Social Care, Brunel University

2. Senior Lecturer, University of Chichester

Address for Correspondence: Liz Griffiths, Dept of Health and Social Care, Brunel University, Mary Seacole Building, Uxbridge UB8 3PH. elizabeth.griffiths@brunel. ac.uk

31 Journal of Practice Teaching 6(3) 2005, pp.31-44

(C) 2005 Whiting and Birch 
Liz Griffiths, Lynn Sayer, May Ryan, Nessie Shia, and Rick Fisher

\section{Introduction}

Across Higher Education, the use of Personal Development Plans (PDPs) has been promoted to encourage the development of key skills in response to employers' expectations that graduates, regardless of discipline, should display flexibility and autonomy in their approach to work. During the same period requirements to demonstrate continuing professional development in order to maintain membership of professional bodies have been evident within the healthcare professions. (Challis, 2000).

The challenge of personal development planning for nurses is not without some professional risk, as areas to improve practice are being exposed as well as strengths. However the positive benefit of PDPs may be encouraged, for, as well as being a very useful way of recording competence, they can represent investment in personal achievement and professional employability (RCN, 2003).

The Quality Assurance Agency (QAA) has defined personal development planning as the way in which individuals can reflect on their own learning and achievement in order to plan for personal, educational and career development (QAA, 2004).

This paper will consider the following:

- The context for the study

- The challenge of introducing PDP

- An action research approach

- Discussion and Conclusion

\section{The Study Context}

The Nursing and Midwifery Council (NMC) requires higher education institutions to undertake re-approval of professional nursing courses every five years. As a consequence Brunel University's portfolio of BSc and Postgraduate Diploma/MSc Community Health Nursing (Community Specialist Practitioner) courses were due for approval during the academic year 2002/2003. News that a full re-validation was required, although stressful, proved to be the catalyst to propose some innovative practices that the core team of lecturers, Community

32 Journal of Practice Teaching 6(3) 2005, pp.31-44 $\quad$ (c) 2005 Whiting and Birch 
Practice Teachers (CPTs) and Mentors could develop. Consequently, by November 2002 a Curriculum Planning Team consisting of the teaching team, managers from Primary Care Trusts, CPTs/Mentors and Practice Educators had been set-up and started to meet. A central plank of the innovations was the development of a formalised framework of professional development planning using an action research approach to implement the changes to the course design.

\section{The challenge}

The rapid expansion of students in higher education is causing many institutions to manage the quality and standards of students' learning more creatively (Cottrell, 2003). Based on recommendations from the Dearing Report (NCIHE, 1997), students are now seen less as passive recipients of education and more as active partners of systems and programmes which meet their needs and aspirations.

The Student Charter (NUS, 1993) suggests that every student should participate in the creation of a record of achievement. This record should be fairly detailed and up-to-date and is formalised as a PDP, which is part of the Higher Education Progress file that is now being introduced across all levels of Higher Education (LTSN, 2002). This Progress File consists of two elements, a transcript with academic achievements and also a means by which students can monitor, build and reflect upon their personal development. The process enables learners to understand and reflect on their achievements and to present those achievements to employers, institutions and other stakeholders.

In the practice setting, the National Health Service Knowledge and Skills Framework (NHS KSF) (DoH, 2004) emphasises the importance of personal development planning in the planning stage of the review process. The primary focus enables nurses to effectively meet the demands of their current post and for the organisation to support individual nurses in developing career progression.

Tamkin et al (1995) caution that where PDPs may be used in employment settings during formal processes such as selection then this may affect the honesty of the content and issues of confidentiality should be considered. If organisations want employees to own their development then a critical balance needs to be achieved between

33 Journal of Practice Teaching 6(3) 2005, pp.31-44 C 2005 Whiting and Birch 
encouragement and control. Central to the idea of PDP are the core characteristics of self-regulated learning, where students can identify goals, exercise choice in planning and carrying out tasks and reflect on the outcome in order to evaluate progress. This process seems to fit very comfortably with the ethos of Post-Registration Education and Practice (PREP) requirements (NMC, 2002).

\section{Action research}

Changing practice to improve the quality of the educational experience for the student can be implemented using an action research approach and was the chosen method in this study. Winter (1996) suggests that this method can be a way of investigating professional practice in a continuously developing sequence and similarly Bryant (1996) emphasises the involvement of the practitioner, collaboration and the link between reflection and improving practice. According to Depoy $\&$ Gitlin (1994) all those who experience a phenomenon are the most qualified to investigate it. This is further supported by Denscombe (1998) and Winter (1996) who argue that practitioners must be participants, in the sense of being partners in the research process. Webb (1996) questions why action research must consist of a group process as there can never be an assurance that the interests of all are in common. However, it was used in this project as it allowed for the inclusion in the process of the various stakeholders including the Higher Education Institution, students, teaching team, CPTs, mentors and employers. Action research is a vehicle in the continuous quest to improve practice in a dynamic and exciting way and was chosen to inform the ongoing improvement of educational experience and practice through the introduction of the PDP.

The action research cycle adopted to plan this study was as suggested by McNiff et al (1996), using a structured, logical approach, that consisted of a number of cycles of implementation, review and modification.

34 Journal of Practice Teaching 6(3) 2005, pp.31-44 (C) 2005 Whiting and Birch 


\section{The research cycles}

- Collaborative planning

- Implementation

- WebCT ${ }^{1}$ development

- Review and evaluation

- Revision of documentation

- Practical outcome

The first cycle involved the Curriculum Planning Team who met regularly during the pre-validation period. It was decided that the implementation of PDPs would be a collaborative process undertaken both in the university within the existing tutorial framework and concurrently in practice on a monthly basis. These plans were then circulated, to a wider consultation group for review, and when finalised, the following guidance was incorporated into course handbooks for approval at Course Validation (see figure 1).

Figure 1

Guidance for Personal Development Planning

\begin{tabular}{l}
\hline $\begin{array}{l}\text { Students will undertake an initial assessment both in university and practice based on } \\
\text { previous experience and level of study of their strengths and areas for learning } \\
\text { development. The advantage of this approach is that individual needs will be addressed at } \\
\text { an early stage of the course and action plans instigated. }\end{array}$ \\
\hline $\begin{array}{l}\text { These action plans will be reviewed on a monthly basis to evaluate progress and } \\
\text { contribute to evidence of development that can be included in the Professional Practice } \\
\text { Portfolio. }\end{array}$ \\
\hline $\begin{array}{l}\text { It will be the student's responsibility to write up their PDP and learning review/action } \\
\text { plans. }\end{array}$ \\
\hline $\begin{array}{l}\text { The tri-partite approach of student, CPT/Mentor and Lecturer can be consolidated during } \\
\text { practice placement visits by the university lecturer. }\end{array}$ \\
$\begin{array}{l}\text { The PDP will form the basis for assessment of development needs during the period of } \\
\text { Consolidated Practice at the end of the course and continue to inform learning needs after } \\
\text { qualifying. }\end{array}$ \\
\hline
\end{tabular}

The second cycle that began with the implementation of the PDP strategy at the beginning of the academic year 2003/2004 was achieved in a number of ways. During the course induction week all students and those CPT/Mentors who could attend were introduced to the documentation, to try and ensure a consistent approach across all pathways and settings. The documentation (see figure 2 below) was

35 Journal of Practice Teaching 6(3) 2005, pp.31-44 C 2005 Whiting and Birch 
designed in duplicate so that all parties in the encounter could keep copies of the interaction.

The purpose of the PDP and the proposed tri-partite approach were explained and students were invited to prepare their first learning assessment for a tutorial with their personal tutors, during the first two weeks of the programme. Likewise in their practice placements, the same approach was suggested. This is in line with the QAA objective to help students articulate personal goals and evaluate progress (QAA, 2004).

Placement visits to those CPT/Mentors who could not attend the initial induction session were arranged as a priority and during the placement audit process the same information regarding the PDP strategy was relayed. This contact was recorded on the placement visit documentation currently in use at this university.

Figure 2

Personal Development Form

\section{PERSONAL DEVELOPMENT PLAN}

STRENGTHS

AREAS TO DEVELOP

ACTION PLAN
\begin{tabular}{|c|c|c|}
\hline DATE & ACTION & MODULE \\
\hline & & \\
\hline & & \\
\hline & & \\
\hline
\end{tabular}

SIGNED STUDENT

CPT/MENTOR

LECTURER

DATE NEXT MEETING

36 Journal of Practice Teaching 6(3) 2005, pp.31-44 (C) 2005 Whiting and Birch 
During the CPT/Mentor study day at the university in November 2003, small group discussion by those present on the experience of using PDPs in practice during the year produced some interesting comments (see Figure 3).

Figure 3

Feedback from small group discussion

Students need a longer period of orientation to working in the community if it is their first community practice experience before completing their first PDP in practice.

For these students PDP appointments could be arranged following an orientation period.

Some students have difficulties in expressing their weaknesses.

Notes from this meeting were circulated to those who were unable to attend, as well as those who did attend. This strategy was advocated by the NMC visitors during the 2002/2003 Annual Monitoring and Review process for the Community Health Nursing portfolio delivered by the university to try and ensure consistent communication.

\section{WebCT development}

During this first year of implementation the university were developing a framework for personal and professional development using the university's chosen media platform WebCT. The Unit leader responsible for developing the university framework was keen to collaborate with the Community Health Team to develop Web-based interactive materials tailored to the needs of CPTs/Mentors and students. In November 2003 the Unit leader undertook a presentation to the community practice teachers and mentors outlining the potential use of Web-based PDP materials for them and their student. Unanimous enthusiasm led the teaching team with the support of the Unit leader to adapt the materials for the CPTs/Mentors. At the next CPT/Mentor meeting in March 2004 hard copies of the materials were distributed to small groups during a PDP workshop. They reviewed the materials and fed back those, which would be of use and how they could be adapted to suit this purpose. The materials were then finalised by the course team for placing on WebCT, and a website was set up for community health mentors, community practice teachers and students. In addition to containing

37 Journal of Practice Teaching 6(3) 2005, pp.31-44 C 2005 Whiting and Birch 
Liz Griffiths, Lynn Sayer, May Ryan, Nessie Shia, and Rick Fisher

the PDP materials, this site also had links to other relevant websites to act as a resource for professional development planning.

The site went live at the beginning of 2004/2005 and was launched to CPTs/Mentors at the first meeting of the year in September 2004. Use of the library, including lending rights was also included as part of the package, as a result community practice teachers and mentors are not only able to support their students' professional development planning but also their own. The site has proved popular and those using it have started to provide feedback on items they would like to see added to the site. The Community Health Team are able to track the use of the website and are able to gauge how well it is used. The potential for this site is just beginning to be realised as in the future it is hoped the site will be used for lecturers and CPTs/Mentors to interact and provide a broader range of relevant documentation to aid professional development planning.

\section{PDPs as part of the assessment strategy}

Also at the study day in March 2004 specific examples were provided of how the PDPs could be used to contribute as evidence for meeting module learning outcomes showing learning development. For example, knowledge gained from appraising literature on a topic or from a practical opportunity such as undertaking an assessment. The following day all the students were given the same examples and explanation, and a chance to share their own experiences so far. At this stage it was clear to the teaching team that there were some inconsistencies of approach in practice, particularly regarding the frequency of PDP meetings and an attempt was made to address these at subsequent placement visits.

\section{Further review}

At the final study day in May 2004 there was an opportunity for students and CPT/Mentors to evaluate what was for many, their first experience of the use of Personal Development Plans. Students commented that using PDPs in practice and in the University had been beneficial and

38 Journal of Practice Teaching 6(3) 2005, pp.31-44 $\quad$ (c) 2005 Whiting and Birch 
CPTs/Mentors also found the PDPs useful for themselves as well as their students. It was also noted that making time for PDPs both in practice and university had been achievable.

\section{Team evaluation}

Within the action research cycle, the evaluation of the strategy by the teaching team so that modifications could be made before the start of the next academic year identified the following evidence.It was acknowledged that the initial plan of undertaking PDP in the university setting on a monthly basis had been too ambitious, particularly for part-time students, although in the practice environment this timing seemed to suit all involved.

Although the PDP form indicated 'Areas to Develop' rather than Weaknesses, it was felt that this needed better initial clarification to enable CPTs/Mentors to promote more accurate self-appraisal by the student. Difficulties in self-appraisal were also found by Spence and El-Ansari (2004), who identified that students tend to recurrently under-estimate their skills. It was also decided to include in the course documentation the specific examples introduced during the year, for using PDPs as evidence, to assist in compiling the Practice Portfolio. This could then be referred to throughout the course.

\section{Final research cycle}

These modifications were implemented for the start of the next academic year and as the study gained momentum, the new group of CPTs/Mentors were engaged in some further developments. It should be noted that there was the normal turnover of CPTs/Mentors ensuring continuity of experience but also the potential for the expression of new ideas.

At a workshop in November 2004, again in small groups, participants were asked to consider the processes involved in undertaking PDPs with students. Some suggestions were made by the Community Health Team to focus the discussion in the broad categories of:

39 Journal of Practice Teaching 6(3) 2005, pp.31-44 @ 2005 Whiting and Birch 
- Managing the Process;

- Using resources to assist in the process;

- Helping the student to set measurable goals;

- Helping the student to set a time frame for achievement of goals;

- Monitoring progress.

All groups chose to consider the suggested aspects and reported back their findings.

From this feedback a number of tips for best practice have been developed to help the future use of PDPs within the course. The results of this work, presented in the format below have also been shared with managers and student community practice teachers and will be incorporated into course documentation for the forthcoming year.

\section{Tips for best practice}

\section{Managing the process}

- The process should be ongoing and mentors must make sure they have protected time with the student. Regular meetings should be held between the mentor and student to discuss PDP issues and these should be at a minimum of monthly intervals.

- Regular frequent review is central to the process. Regardless of the time interval used, it is important to set a timeframe for these meetings. The time frame must be flexible according to student's progress and perhaps also due to opportunities for learning, which present whilst the student is in the placement.

- Both mentor and student must be committed to the process.

- There is a need to identify the student's strengths and developmental needs at an early stage.

- Progress can be helped by having student centred objectives and by the mentor assessing the student's learning style.

- The process should be guided by the Learning Outcomes (LOs) of the course. Students could address these in manageable steps. Reflective diaries and critical incidents could be explored and mapped to the LOs. In this way it is possible to relate theory to practice.

$40 \quad$ Journal of Practice Teaching 6(3) 2005, pp.31-44 (C) 2005 Whiting and Birch 
- Where students are new to the discipline, it is desirable for them to carefully explore their transition from hospital to community nursing.

\section{Using resources}

- The environment is an important feature. Try to ensure a private space for student and meetings

- It is important to allocate the student time to work with others; using colleagues judiciously has a two-way effect. It can enable a mentor to gain some 'triangulated' evidence concerning the student's progress and also alleviate some of the pressures associated with working in close proximity to the student. This process can be expanded to allocating the student within the wider Primary Care team.

- Students should be observed, as a way of monitoring their performance.

- Experience of having mentored previous students could be viewed as a 'template' around which to structure their current mentoring role.

- Other recommended resources include 'local online information' and access to professional journals.

\section{Helping the student to set measurable goals}

- Breaking down the learning outcomes into smaller 'mini' or 'micro' goals can help some students. Goals should be broken down into individual areas of practice.

- A 'SWOT' analysis with the student can help formulate pieces of the jigsaw to complete the whole picture. (An analysis of strengths, weaknesses, opportunities, threats, a useful tool for taking stock of a new situation)

- The PDP could be related to a practical issue and reviewed in the following months PDP to see if it has been achieved.

- Students should examine their own strengths and areas to develop. Using support and guidance from mentors these can be monitored regularly.

41 Journal of Practice Teaching 6(3) 2005, pp.31-44_@ 2005 Whiting and Birch 


\section{Helping the student to set a timeframe}

- Students can be assisted in setting short, medium, and long- term goals.

- Kolb's cycle can be used to reflect and review. (An experiential learning model: Kolb 1984).

- Objectives should be set using a 'SMART' approach and monitored by reflection. (Specific; Measurable; Achievable; Realistic; Timebound goals for target setting).

\section{Monitoring progress}

- Progress should be monitored as an ongoing, weekly/monthly process. Mentors should observe difficulties experienced by the student and note what steps they are taking to achieve the goal.

- Time management is important to ensure that objectives can be completed.

- Progress should be monitored by evaluating how well the student has met the LOs.

\section{Discussion}

This exciting project has re-enforced the notion of collaboration between all those involved in the implementation of a change of practice. An action research approach provided a dynamic and evaluative method over time. The coincidental development of the university WebCT support was an unexpected bonus and has proved to be a useful tool in complementing the process, especially as CPTs/Mentors and students can access the site from the practice setting. The teaching team have found the tool beneficial in analysing the student's own learning needs and monitoring academic progression.

As can be seen from feedback at key points the use of the PDP has been well evaluated by all involved as a way of continuously monitoring progress. An unexpected finding was that PDPs can help the student with time management but that flexibility with the process was also necessary. The development of completed examples of PDPs in the

42 Journal of Practice Teaching 6(3) 2005, pp.31-44 C 2005 Whiting and Birch 
handbook and 'Tips for Best Practice' were practical developments of review and evaluation.

The significant results indicate that PDP should be an ongoing process of objective setting and review during a student's placement. The process should be guided by course learning outcomes, but that these can be broken down into smaller achievable goals to ensure successful completion. If time is allocated to the process on a regular basis, then evaluation of progress can be assessed and any difficulties identified promptly to enable remedial action planning to be agreed. Currently the PDP process has tended to be paper based but the potential for a fully computerised method is possible as all the documentation is available on WebCT. A decision will be required whether to continue with the dual system in future. The next stage, as yet to be resolved, is encouraging students to own the responsibility and take the initiative in managing the process, particularly in practice.

\section{Conclusion}

Personal Development Planning may not satisfy all the demands of continuing professional development but can give the learner the skills to recognise the challenges that will be encountered in practice, particularly as the professional career path becomes ever more complex (Challis, 2000). Although this particular project was undertaken with nurses working in community settings it is hoped that the lessons learned could prove useful to all working in the caring field who support students in practice.

In the university setting this initiative has become a useful addition to the Community Health Nursing programme and the team look forward to further developments to enhance the student learning experience.

\section{Editor's note}

1. WebCT $=$ "Web Course Tools', a Virtual Learning Environment.

43 Journal of Practice Teaching 6(3) 2005, pp.31-44

(C) 2005 Whiting and Birch 
Liz Griffiths, Lynn Sayer, May Ryan, Nessie Shia, and Rick Fisher

\section{References}

Bryant, I. (1996) Action research and reflective practice. in D. Scott and R. Usher (Eds.) Understanding Educational Research. London: Routledge

Challis, M. (2000) AMEE Medical Education Guide No. 19: Personal learning plans. Medical Teacher, 22, 3, 225-236

Cottrell, S. (2003) Skills for Success: The personal development planning handbook. Basingstoke: Palgrave

Denscombe, M. (1998) The Good Research Guide: For small scale social research projects. Buckingham:. Open University Press

Depoy, E., and Gitlin, L. (1994) Introduction to Research: Multiple Strategies for Health and Human Sciences. St Louis: Mosby

Kolb, D.A. (1984) Experiential Learning. London: Prentice Hall.

Learning and Teaching Support Network (2002) Guide for Busy Academics. No.1. Personal Development Planning. York: LTSN Generic Centre

McNiff, J., Lomax, P., and Whitehead, J. (1996) You and Your Action Research Project. London: Routledge

National Committee of Inquiry into Higher Education (1997) [Dearing Report] Higher Education in the Learning Society. London: HMSO

Department of Health (2004) The NHS Knowledge and Skills Framework and the Development Review Process. London: DoH

National Union of Students (1993) NUS Student Charter. London: NUS.

Nursing and Midwifery Council (2002) The PREP Handbook. London: NMC

Royal College of Nursing (2003) Personal Development Planning. Nursing Standard Essential Guide. London: RCN Publishing

Spence, W., ans El-Ansari, W. (2004) Portfolio assessment: Practice teachers' early experience. Nurse Education Today, 24, 388-401

Tamkin, P., Barber, .L, and Hirsh, W. (1995) Personal Development Plans: Case studies of practice. IES report 280. www.employment-studies.co.uk/summary

The Quality Assurance Agency for Higher Education (2004) Progress files for Higher Education. iwww.qaa.ac.uk/crntwork/progfilehe/contents.htm.

Webb, G. (1996) Becoming critical of action research for development. in O. Zuber-Skerrit (Ed.) New Directions in Action Research. London: Falmer Press

Winter, R. (1996) Some Principles \& Procedures for the Conduct of Action Research in O. Zuber-Skerrit (Ed.) New Directions in Action Research. London: Falmer Press

44 Journal of Practice Teaching 6(3) 2005, pp.31-44

(C) 2005 Whiting and Birch 